\title{
Breaching of fluvial dykes: influence of the dyke geometry
}

\author{
Vincent Schmitz ${ }^{1}$, Sébastien Erpicum ${ }^{1}$, Ismail Rifai ${ }^{2}$, Kamal El Kadi \\ Abderrezzak $^{3,4}$, Pierre Archambeau ${ }^{1}$, Michel Pirotton ${ }^{1}$, Benjamin Dewals ${ }^{1}$ \\ ${ }^{1}$ University of Liège, Hydraulics in Environmental and Civil Engineering (HECE), Liège, Belgium \\ ${ }^{2}$ Egis, Guyancourt, France \\ ${ }^{3}$ National Laboratory for Hydraulics and Environment (LNHE), EDF R\&D -, Chatou, France \\ ${ }^{4}$ Saint Venant Laboratory for Hydraulics, Chatou, France
}

\begin{abstract}
Fluvial dyke breaching is a major concern for flood risk management; but the mechanisms of dyke breaching remain incompletely understood. We report here on forty (40) laboratory tests performed to assess the influence of the geometry of dykes made of non-cohesive sediments on the evolution of the breach discharge. Three parameters were systematically varied: the side slopes of the dyke and its crest width. Each geometric configuration was tested for several main channel inflow discharges. Results show that the breach discharge grows faster when the dyke volume becomes smaller and when the inflow discharge is increased. All geometrical parameters were then lumped into a single non-dimensional parameter and a characteristic time was defined to quantify the growth rate of the breach discharge. For a given inflow discharge, the proposed characteristic time increases linearly with the non-dimensional parameter.
\end{abstract}

\section{INTRODUCTION}

Failure of fluvial dykes often leads to devastating consequences in the protected areas. Various factors can trigger dyke breaching but overtopping flow is by far the most frequent cause of failure. Nevertheless, the breaching mechanisms are still not well understood, and the prediction of the breach expansion and outflow hydrograph remains challenging.

So far, most experimental studies have focused on overtopping of dykes perpendicular to the main flow (e.g. Asghari Tabrizi et al. 2017, Müller et al. 2016, Schmocker \& Hager 2012), while few analyzed fluvial dykes, i.e. dykes parallel to the main flow (Michelazzo et al. 2018, Wei et al. 2016). Recently, Rifai et al. (2017, 2018, 2020) performed fifty-four (54) laboratory tests of fluvial dyke breaching to assess the influence of the main channel inflow discharge, the downstream boundary conditions, the floodplain tailwater, the channel size as well as the bottom erodibility and dyke material. All corresponding data are publicly available (Rifai et al. 2019). In contrast, the influence of the dyke geometry was never investigated systematically for the case of fluvial dykes.

Here, we present forty (40) new laboratory tests carried out to highlight the influence of the dyke upstream and downstream side slopes as well as the crest length on the breaching process of fluvial dykes made of non-cohesive sediments. A similar study was conducted by Müller et al. (2016) in the frontal configuration. Here, we specifically investigate the influence of the dyke geometry on the breach hydrograph. In particular, the growth rate of the breach discharge is critical for real-world flood risk analysis and emergency planning, so that its analysis is of practical relevance. 


\section{EXPERIMENTAL SETUP}

The laboratory setup is the same as that used by Rifai et al. (2017, 2018). It consists of a horizontal, straight main channel (10 m x $1 \mathrm{~m}$ ) with a 3-meter-long lateral opening toward a floodplain ( $4.3 \mathrm{~m} \times 2.5 \mathrm{~m})$. Along the side opening, sand was gathered and compacted to build a trapezoidal shaped fluvial dyke, whose dimensions were systematically modified while keeping the dyke height constant $(0.3 \mathrm{~m})$. The dyke geometry is characterized by the upstream slope $S_{u}$, the downstream slope $S_{d}$ and the crest length $L_{k}$ (Figure 1 ).

A specific coating was applied on the surfaces of the main channel and the floodplain to ensure roughness continuity between those surfaces and the dyke. The bottom of the main channel and the floodplain were at the same level and elevated by $0.7 \mathrm{~m}$ compared to the outflow tanks. To avoid seepage flow, a drainage system was installed at the dyke bottom. Finally, a perforated plane followed by a tank were placed at the end of the main channel to control the downstream water level and to collect the main channel outlet flow.

Each geometrical configuration was tested with three different main channel inflow discharges, i.e. $Q_{\text {in }}=25 \mathrm{l} / \mathrm{s}, 40 \mathrm{l} / \mathrm{s}$ and $55 \mathrm{l} / \mathrm{s}$. The inflow discharge was kept constant and supplied at the upstream end of the main channel. During the filling phase, the water level rose in the main channel. The perforated plate was tuned such that at equilibrium the water level corresponded to the dyke height. Before starting the tests, a 2-cm-deep and 10-cm-wide notch was created in the dyke crest to trigger breaching. Once the water level overtopped the notch, erosion and breaching developed.

The water level in the main channel was measured and recorded in three locations using ultrasonic sensors (accuracy of $\pm 1 \mathrm{~mm}$ ). Similar sensors were used to monitor the water level in the outflow tank and in the drainage tank. The inflow discharge was measured using an electromagnetic flowmeter (accuracy of $\pm 4 \%$ ). The breach discharge was determined from mass balance considering the main channel inlet and outlet flows, storage in the main channel, as well as the drainage flow.

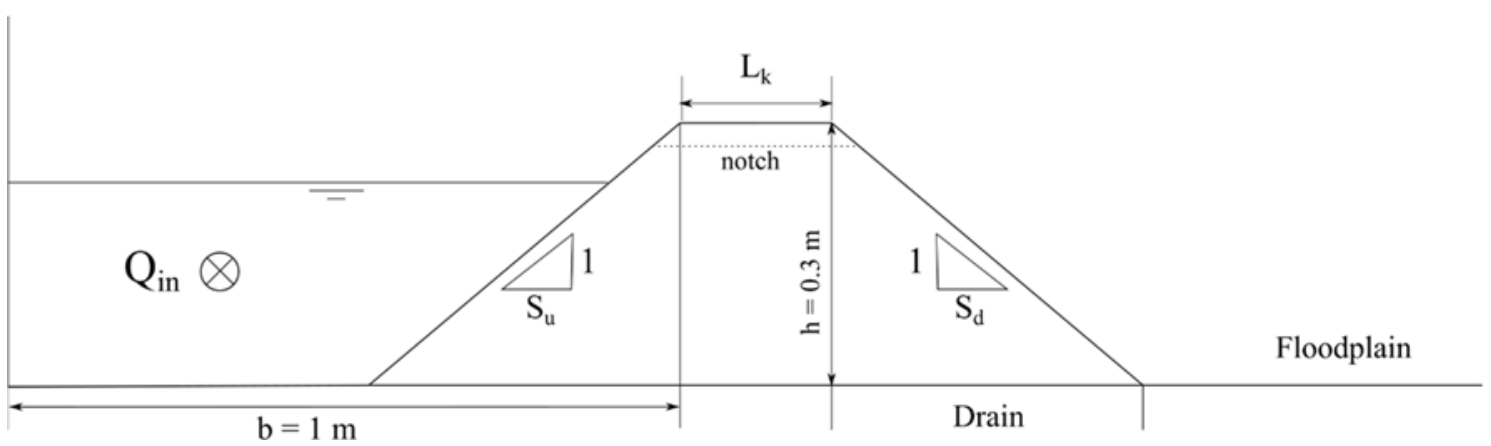

Figure 1. Sketch of a dyke vertical profile, highlighting the main geometric parameters: upstream and downstream slopes $\left(S_{u}\right.$ and $\left.S_{d}\right)$, dyke height $(h)$ and crest length $\left(L_{k}\right)$. The main channel width $b$ is $1 \mathrm{~m}$.

\section{RESULTS}

The focus has been set on the time evolution of the breach discharge, $Q_{b}$. Figure 2 provides examples of the observed hydrographs. Each subfigure highlights the influence of a particular geometrical parameter (the upstream slope and the crest length, respectively), while keeping the other parameters constant. Note that the time frame is limited to $200 \mathrm{~s}$ to highlight the impact of the geometry on the beginning of the breaching phenomenon.

The breach hydrographs depend highly on the inflow discharge, $Q_{i n}$. When $Q_{i n}$ is relatively small, the breach discharge evolution exhibits an overshoot, which is damped when the dyke volume is increased (e.g. when parameter $S_{u}$ is increased from 1.5 to 2). This trend is confirmed by the repeatability of the tests, as shown for $S_{u}=2$. Similarly, the overshoot fades when the inflow discharge rises, as can be seen in Figure $2 \mathrm{~b}$. 


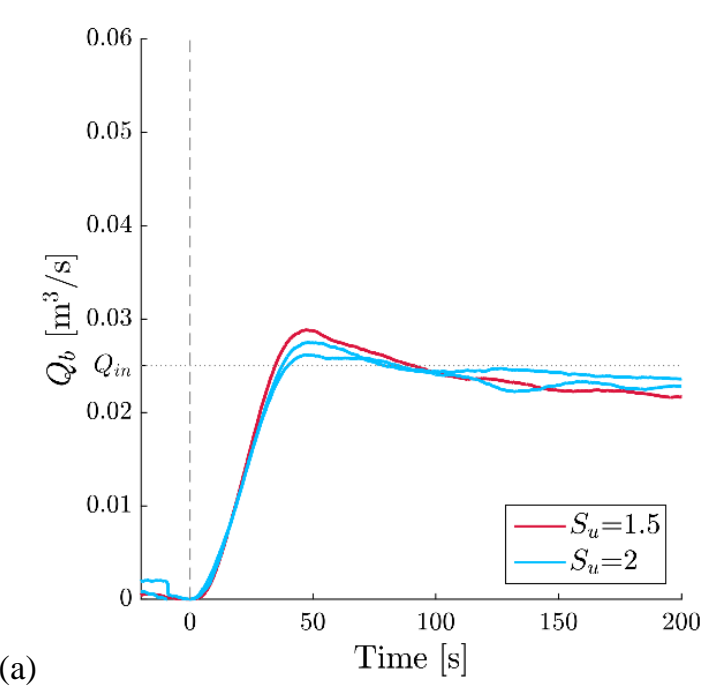

(a)

Figure 2. Examples of measured hydrographs: (a) effect of varying the upstream dyke slope, with $Q_{\text {in }}=25 \mathrm{l} / \mathrm{s}$; (b) effect of varying the crest length, with $Q_{i n}=55$ l/s.

Rifai et al. (2017) defined as "Stage 1" the phase of rapid breach deepening and widening, corresponding to a steep increase in breach discharge. It is generally followed by a phase of gradual breach widening (Stage 2). Figure $2 \mathrm{~b}$ shows that during Stage 1, the growth rate of the breach discharge is considerably influenced by the dyke geometry: a larger crest length $L_{k}$ (i.e. a higher dyke volume) leads to a substantially reduced growth rate of the breach discharge, which nonetheless seems to tend in the long run toward a similar equilibrium breach discharge independently of the dyke geometry. As shown in Figure 2a, the dyke upstream slope has a similar influence, although its impact is less marked.

Here, we chose to characterize this growth rate through the time $t_{50 \%}$ needed for the breach discharge to reach half of its equilibrium value. Note that in Figure 2a, the breach discharge reaches an equilibrium value after about $150 \mathrm{~s}$. In contrast, for higher inflow discharges in the main channel, the equilibrium breach discharge is reached much later (Figure 2b). Although not displayed in Figure 2b, our measurements extended over 400 to $600 \mathrm{~s}$ (depending on the test), which is sufficient to identify the equilibrium breach discharge even for $Q_{\text {in }}=55 \mathrm{l} / \mathrm{s}$. The time frame shown in Figure $2 \mathrm{~b}$ was chosen to emphasize the influence of the geometric parameter $L_{k}$ on Stage 1 of the breaching as well as on the beginning of Stage 2.

The results show that the characteristic time $t_{50 \%}$ systematically increases with the dyke volume. When plotted against each of the geometric parameters, namely $S_{u}, S_{d}$ and $L_{k}$, the time $t_{50 \%}$ varies essentially linearly.

In line with Müller et al. (2016), the various geometric parameters were lumped into a single non-dimensional unit volume parameter $(\mu)$, which writes:

$$
\mu=\frac{1}{2}\left(S_{u}+S_{d}\right)+\frac{L_{k}}{h},
$$

Again, the time $t_{50 \%}$ follows a linear trend when plotted against $\mu$ (Figure 3 ). Note that the higher the inflow discharge in the main channel, the stronger the variations of $t_{50 \%}$ with the dyke geometry. The obtained slopes are equal to 12, 22 and $30 \mathrm{~s}$ for $Q_{\text {in }}=25,40$ and 55 l/s, respectively. 


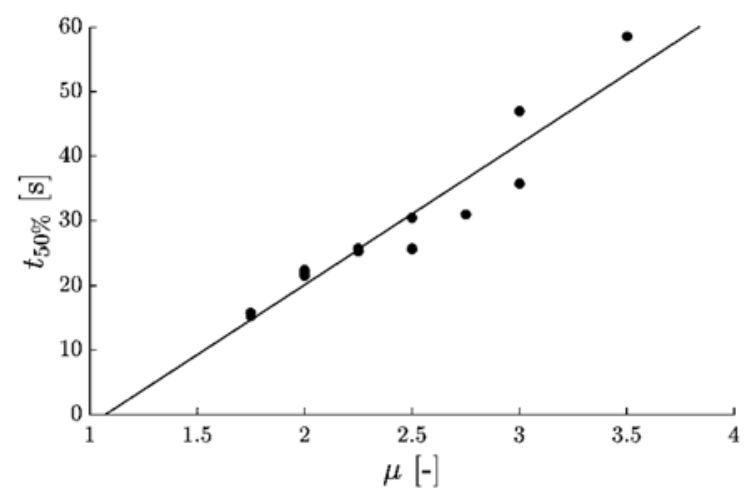

Figure 3. Characteristic rising time $t_{50 \%}$ as a function of the non-dimensional volume parameter $\mu$. The inflow discharge is equal to $40 \mathrm{l} / \mathrm{s}$.

\section{CONCLUSION}

Based on forty (40) new laboratory tests of fluvial dyke breaching, we highlighted the influence of the dyke geometry on the breach hydrograph. The growth rate of the breach discharge decreases when the dyke volume is increased as a result of a change in the dyke upstream or downstream slopes $\left(S_{u}\right.$ or $\left.S_{d}\right)$ or in the crest length $\left(L_{k}\right)$. The occurrence of an "overshoot" in the breach hydrograph is also affected by the dyke geometric characteristics. Moreover, the influence of the dyke geometry tends to be magnified when the inflow discharge in the main channel is higher.

Results showed that the combined effect of the three studied geometrical parameters $\left(S_{u}, S_{d}\right.$ and $L_{k}$ ) can be lumped into a single non-dimensional parameter $(\mu)$, as introduced by Müller et al. (2016) for the frontal configuration. A characteristic time $t_{50 \%}$ was then selected to characterize the rate at which the breach discharge increases during each test. For a given inflow discharge, it appeared that $t_{50} \%$ exhibits a positive linear dependency with the non-dimensional volume parameter $\mu$.

These findings make a valuable step toward a better understanding of the breaching dynamics of fluvial dykes. Additionally, future work will be focused on a non-dimensional expression for the characteristic time in order to generalize the outcomes of the study.

\section{REFERENCES}

Asghari Tabrizi, A., Elalfy, E., Elkholy, M., Chaudhry, M. H., \& Imran, J. (2017). Effects of compaction on embankment breach due to overtopping. Journal of Hydraulic Research, 55(2), 236-247.

Michelazzo, G., Oumeraci, H., \& Paris, E. (2018). New hypothesis for the final equilibrium stage of a river levee breach due to overflow. Water Resources Research, 54(7), 4277-4293.

Müller, C., Frank, P. J., \& Hager, W. H. (2016). Dyke overtopping: effects of shape and headwater elevation. Journal of Hydraulic Research, 54(4), 410-422.

Rifai, I., Erpicum, S., Archambeau, P., Violeau, D., Pirotton, M., El Kadi Abderrezzak, K., \& Dewals, B. (2017). Overtopping induced failure of noncohesive, homogeneous fluvial dikes. Water Resources Research, 53(4), 3373-3386.

Rifai, I., El Kadi Abderrezzak, K., Erpicum, S., Archambeau, P., Violeau, D., Pirotton, M., \& Dewals, B. (2018). Floodplain Backwater Effect on Overtopping Induced Fluvial Dike Failure. Water Resources Research, 54(11), 9060-9073.

Rifai, I., El kadi Abderrezzak, K., Erpicum, S., Archambeau, P., Violeau, D., Pirotton, M., \& Dewals, B. (2019). Flow and detailed 3D morphodynamic data from laboratory experiments of fluvial dike breaching. Scientific data, 6(1), 53.

Rifai, I., El Kadi Abderrezzak, K., Hager, W., Erpicum, S., Archambeau, P., Violeau, D., Pirotton, M., \& Dewals, B. (2020). Apparent cohesion effects on overtopping-induced fluvial dike breaching. Journal of Hydraulic Research. In press. https://doi.org/10.1080/00221686.2020.1714760.

Schmocker, L., \& Hager, W. H. (2012). Plane dike-breach due to overtopping: Effects of sediment, dike height and discharge. Journal of Hydraulic Research, 50(6), 576-586.

Wei, H., Yu, M., Wang, D., \& Li, Y. (2016). Overtopping breaching of river levees constructed with cohesive sediments. Natural Hazards and Earth system sciences, 16(7), 1541-1551. 